\title{
Research
}

\section{Experiences of front-line health professionals in the delivery of telehealth:}

\author{
a qualitative study
}

\begin{abstract}
\section{Background}

Telehealth is an emerging field of clinical practice but current UK health policy has not taken account of the perceptions of frontline healthcare professionals expected to implement it.
\end{abstract}

\section{Aim}

To investigate telehealth care for people with long-term conditions from the perspective of the front-line health professional.

\section{Design and setting}

A qualitative study in three sites within the UK IKent, Cornwall, and the London Borough of Newham) and embedded in the Whole Systems Demonstrator evaluation, a large cluster randomised controlled trial of telehealth and telecare for patients with long-term and complex conditions.

\section{Method}

Semi-structured qualitative interviews with 32 front-line health professionals ( 13 community matrons, 10 telehealth monitoring nurses and 9 GPs) involved in the delivery of telehealth.

Data were analysed using a modified grounded theory approach

\section{Results}

Mixed views were expressed by front-line professionals, which seem to reflect their levels of engagement. It was broadly welcomed by nursing staff as long as it supplemented rather than substituted their role in traditional patient care. GPs held mixed views; some gave a cautious welcome but most saw telehealth as increasing their work burden and potentially undermining their professional autonomy.

\section{Conclusion}

Health care professionals will need to develop a shared understanding of patient self-management through telehealth. This may require a renegotiation of their roles and responsibilities.

\section{Key words}

primary care; qualitative; telehealth, Whole System Demonstrator.

\section{INTRODUCTION}

Telehealth is the remote exchange of data between a patient and healthcare professional to assist in the diagnosis and management of health, generally provided to patients with long-term health conditions. It offers the possibility of early detection of deteriorations in health and prompt response from the healthcare system. In addition, it is a potentially promising strategy in facilitating greater reliance on self-care by the patient through the delegation of health professional tasks to patients and carers. It may also bring about changes in the practice of care, in the division of healthcare work ${ }^{2}$ and in traditional professional-patient relationships., ${ }^{3,4}$ How health professionals respond to the new technology will be critical to its implementation. ${ }^{5-8}$ Other qualitative research focusing on a specific subset of telehealth in the form of a telephone advice service suggests that healthcare workers have a range of responses, from the reconstruction of new roles and identities to fit the telehealth work, to ambivalence, a sense of protectiveness about maintaining boundaries around established remits. Pinnock and colleagues report that the

V MacNeill, PhD, research fellow, Department of Social and Environmental Health Research, Faculty of Public Health \& Policy, London School of Hygiene and Tropical Medicine, London. C Sanders, PhD, senior lecturer in medical sociology, Centre for Primary Care, Institute of Population Health, The University of Manchester, Manchester. R Fitzpatrick, PhD, professor of public health and primary care, Department of Population Health, University of Oxford, Oxford. J Hendy, PhD, senior lecturer in health care management, Faculty of Business, Economics and Law, Department of Health Care Management and Policy, University of Surrey, Guildford. J Barlow $\mathrm{PhD}$, professor of technology and innovation management, Imperial College Business School, London. M Knapp, PhD, professor of social policy, London School of Economics and Political Science, London. A Rogers, PhD, professor of health systems implementation, Faculty of Health Sciences, University of Southampton, introduction of telehealth has resulted in increasing contact between patients and $\mathrm{GPs}^{10}{ }^{10}$ although this was contradicted in another study on GP and practice nurse contacts with patients which showed no change. ${ }^{11}$ The qualitative study reported here is a component of the Whole System Demonstrator evaluation, a large cluster randomised controlled trial of telehealth and telecare for patients with long-term and complex conditions /chronic heart disease, chronic obstructive pulmonary disease [COPD] and diabetes) and those with social care needs. Details of the trial design are reported elsewhere ${ }^{12}$ but are summarised here in Box 1 and Box 2

This article examines the views and experiences of healthcare professionals caring for patients receiving the telehealth intervention.

\section{METHOD}

\section{Sampling and recruitment}

Three sites (Kent, Cornwall, and the London Borough of Newham) each had a project management team responsible for the roll out and implementation of the whole programme and the project

Southampton. M Bardsley, PhD, director of research, Nuffield Trust, London. SP Newman, $\mathrm{PhD}$, dean of the School of Health Sciences, City University, London.

\section{Address for correspondence}

Virginia MacNeill, Department of Social \&

Environmental Health Research, Faculty of Public Health \& Policy, London School of Hygiene and

Tropical Medicine, 15-17 Tavistock Place, London WC1H 9SH.

E-mail: Virginia.MacNeillalshtm.ac.uk

Submitted: 12 March 2014; Editor's response: 29 April 2014; final acceptance: 27 May 2014.

\section{CBritish Journal of General Practice}

This is the full-length article (published online 30 Jun 2014) of an abridged version published in print. Cite this article as: Br J Gen Pract 2013; DOI: 10.3399/bjgp14X680485 


\section{How this fits in}

There is global interest in telehealth as a means of addressing increasing health care costs. It is also prominent in the UK health policy modernisation agenda. However, telehealth within the UK is a fragmented but emerging field of clinical practice and recent results from the Whole System Demonstrator are equivocal. Nevertheless there is a UK policy imperative driving telehealth forward and front-line staff will be key to its successful and widespread adoption.

managers facilitated the recruitment of potential interview participants for this qualitative study. The sampling strategy was purposeful in seeking to obtain views of enough different key categories of health professionals that delivered telehealth to patients with long-term and complex conditions until data saturation was achieved. Between 2008 and 2010, 32 participants (13 community matrons, 10 telehealth monitoring nurses and nine GPs) were interviewed. Twelve of the 13 community matrons and all 10 monitoring nurses were female and the majority had a community nursing background stretching back at least 20 years. None of the nursing staff approached refused to

\section{Box 1. The telehealth monitoring system}

1. Telehealth equipment was installed in the patient's home and included a monitor unit and appropriate peripheral devices (pulse oximeter, a glucometer and weighing scales).

2.Patients recorded daily key biometric readings including, blood pressure, weight, oxygen, and blood glucose levels.

3. Readings were securely transmitted electronically to healthcare professionals.

4. Incoming readings were automatically classified according to preset parameters specific to the patient.

5. Healthcare providers monitored and took action if data fell outside the specified parameters.

\section{Box 2. The telehealth monitoring process}

\section{The telehealth monitoring service took two distinct forms:}

Nurse service: Nurses remotely monitored and reviewed biometric data of patients not under the care of community matrons.

Community matron service: Matrons monitored biometric data for patients on their caseload, as part of an enhanced, more intensive case management service for patients whose conditions were more advanced than those being monitored by the telehealth nurses.

Community matrons and telehealth nurses responded to monitoring data as follows:

Inside parameters - No further action.

Outside parameters, options included:

- Patients telephoned to discuss reading/ ascertain current health issues.

- Patients were referred to other healthcare professionals such as a GP or secondary care services.

- Community matrons or telehealth nurses visited patient. participate in an interview. An additional 34 GPs were approached through the site project managers or through their own practice managers but only nine agreed to be interviewed. Those that declined gave pressure of work as the principal reason. All nine GP participants were male and had been in practice for at least 15 years.

Each prospective participant was sent an invitation letter and an information sheet about the study and gave formal, written consent at the time of the interview.

\section{Data generation}

Individual, face-to-face interviews were considered the most appropriate method for data collection as this ensured confidentiality. A semi-structured interview guide was developed following a review of literature ${ }^{13-17}$ and discussions between the authors, both health services researchers. The main interview topic areas covered implementation of telehealth at local level, impact on practice, on professional-patient relationships and on interprofessional communication and relationships. The interviews were conducted and took place in participants' work places, except for one telephone interview conducted at the request of one of the GPs. All interviews lasted 30-60 minutes, were digitally recorded, and transcribed verbatim.

\section{Data analysis}

Transcripts were imported into NVivo9, a qualitative data analysis programme. A coding framework was developed that drew on the interview topics and previous research about remote care. The transcripts were analysed using a modified grounded theory approach incorporating the constant comparison technique to elicit key themes and explore deviant cases. ${ }^{18}$ Individual interview data were initially subjected to a process of open coding in which descriptive codes were attached to fragments of data and then compared across all transcripts. These codes were then grouped into sets of thematic categories, Isuch as professional roles, workload management, training needs, inter-professional communications and the role of technology in patient care) and further refined during discussions with input on interpretation from the other co-authors during the drafting of the manuscript.

\section{RESULTS}

Two principal themes emerged from the interviews. The first was health professionals' experiences and perceptions of telehealth as an empowering or 
burdensome influence on patients, and the second was health professionals' experiences and perceptions of telehealth as an enabling or constraining influence on professional development and expertise.

\section{Telehealth as an empowering or burdensome influence on patients}

Telehealth can empower the patient. The vast majority of nursing participants viewed telehealth as a revolutionary and potentially beneficial change in the delivery of health care, as long as it was presented to patients as an optional rather than essential part of their healthcare plan, supplementing rather than replacing traditional health care. Most described it in terms of personal benefits to patients, who, they believed, gained new knowledge about their condition:

'People have really taken to the equipment, really been able to enhance their understanding of their condition. We've had people give up smoking because of it, you know, really things that we never expected, never expected at all. So those have been really, really beneficial.' (Community matron, Cornwall)

In their experience, telehealth patients were becoming adept in recognising a correlation between their health behaviours and their biometric signs, for example the effect of smoking and exercise on the patient with COPD, or the effect of diet on the patient with diabetes:

'What it's done is it's helped patients to think, "Okay, right, well the weather's bad, yes, I understand now why my oxygen levels are low, because today it's a really muggy day." So it's almost reiterating, helping them to see more visually what's going on for them. '(Community matron, Cornwall)

Most nurses did not see age as a barrier to patient use:

I've got a chap in his nineties, 93 years old, who talks to me as if he's a healthcare professional now. And I'm impressed, because sometimes you tend to, you have prejudice "Well the old, they can't use this equipment." Actually that's not my experience, l've been positively surprised. He goes to me, he will say "My SpO2 ..." which is a measure of your oximetry, oxygen level. "SpO2 is this, and I know what it means. That means everything is fantastic. And my weight is this and it's been quite stable. And my blood pressure is ... and my heart rate is within the range of what you want it to be." And / sit there and I am totally amazed.' (Community matron, Newham)

Thus they considered that patients were becoming expert in understanding their condition, leading to behavioural changes and often to improvements in, or stabilising of, their condition and quality of life:

'They understand their long-term condition more now. If a COPD patient felt that they were getting an exacerbation, if they were coughing a little bit more, if their chest was a bit tight and they could see their SpO2s going down, then straight away they would be off to the GP themselves. And probably they would be phoning us and saying "Oh I've been to my GP because l've got a chest infection." Whereas if they are left to their own devices, they didn't have that equipment, they would, they wouldn't know and probably two or three days down the line their chest infection would be getting worse. '(Community matron, Newham)

The nursing staff also believed that now that biometric information was collected via telehealth there was a reduced need for patients living at a distance or in isolated areas to undertake arduous trips to attend routine appointments with their clinician.

Telehealth can burden the patient. While nurse participants extolled the patient benefits of telehealth, a minority of nursing participants and most GPs were more measured in their enthusiasm.

They spoke about the potential burden that telehealth might place on the patients, especially patients whose condition was less advanced and who were relatively active and healthy. In their view, such patients were being prematurely drawn into clinical surveillance and that it caused them too much anxiety without any tangible benefits:

I think there were a small number of people where it actually made them more anxious. A patient was doing his blood pressure about 15 times a day.' (Community matron, Kent)

Paradoxically they also voiced concerns about the appropriateness of telehealth for the very severely ill:

Actually one patient we were dealing very heavily with has stopped because he is really too poorly to use it, he's terminal. So, you know, there is a point where telehealth is quite stressful, if you're at that end 
stage, you know, you don't really need that. (Telehealth nurse, Newham)

Several nurses and GPs also shared the view that patients could become too dependent on the technology and might fail to seek medical help:

'The first thing they do in the morning when they wake up is put on their cup of tea and breakfast and spend half an hour doing all their bits and bobs and I think that raises wider issues in society about the medicalisation of people and people being dependent on, you know, machines telling them whether they're well or not. (GP, Kent)

Equally, there were comments that some patients lacked the strength and manual dexterity required to use some of the peripheral monitoring equipment:

It may be that the equipment is difficult for somebody to use at times, perhaps if they've had, you know, a stroke or something that makes it difficult to actually have, fit the cuff. So the actual use of the equipment sometimes can be a stumbling block for patients. '(Community matron, Cornwall)

\section{Telehealth as enabling or constraining professional development and expertise}

Telehealth can enable professional development and expertise. The nurses reported that use of telehealth was an important new skill, as was the ability to understand trends in the management of long-term conditions:

'The skills l've learned in monitoring the trends, using this approach, have been quite different to how I would normally have approached that patient, so.../ think that's been the biggest probably benefit and new skill.' (Community matron, Cornwall)

As well as a being a positive move in the care of patients with complex longterm conditions, most nurses viewed the introduction of telehealth as an opportunity for professional career development:

It might help me to move up the ladder, if you like, and actually get more qualifications under my belt.' (Telehealth nurse, Newham)

They also viewed it as a chance to increase their clinical knowledge and skills and gain greater freedom to make decisions about patient care, although at the same time they were careful to endorse the GP's continuing authority:

I've got much more knowledge to be able to have open dialogue with them [the GPs]. (Community matron, Cornwall)

Telehealth can constrain professional development and expertise. Telehealth had a polarising effect among the GPs and unlike the nurses, none viewed its introduction as an opportunity to enhance their own professional development or standing, although some welcomed it as a useful addition to health care for patients with complex long-term conditions:

'It [teleheath monitoring] has shifted the focus. Previously we used to manage with the district nurse... now you've got a method of monitoring the patient in their house and using their own skill to inform us. ' (GP, Newham)

However most were opposed to it, with one GP reporting with some exasperation the organisational and bureaucratic difficulties of managing what he called a 'tsunami' of patient monitoring data:

I don't think healthcare would be any worse the wear if tomorrow every telehealth machine was vaporised. '(GP, Kent)

He went on to say:

I don't see why other people should decide this is how / should use my marginal time, when there are other very good calls on my marginal time that might also improve the health or welfare of my patients.' (GP, Kent)

Instead there were tensions between wanting to maintain their central role in caring for their patients and not having the time or resources to do so. Two pointed out that the monitoring might identify problems that they did not have the resources to manage:

'You're suddenly getting information, you didn't have before. So I now know that Mrs B's blood pressure is up and down every day whereas before I would happily convince myself that "I've seen her now, I'm seeing her in a month and it's not too bad." Now 1 know it isn't, I didn't know that before and I didn't have to worry about it. Once you've got that information you've sort of got to decide what to do with it.' (GP, Newham)

Nevertheless most of the GPs interviewed were not speaking from a position of 
direct experience as their involvement with telehealth was limited, comprising occasional contact with patients using the equipment and irregular encounters with some of the monitoring nurses. This was largely because few of their patients were monitored through telehealth:

We've got a few, 10000 patient practice, and there are only a few people with it. Maybe, I can't remember the exact numbers on telehealth, but maybe eight, ten, tops, doing it, so it impacts very little on my working life really, because the numbers are small. (GP, Cornwall)

Interest in telehealth patient data also varied. Some GPs were able to access it from their own desktop computer, but only one of those interviewed had done so, although another GP reported receiving print-outs of the results and discussing them with a telehealth monitoring nurse:

'They don't routinely send me all of the details. [It is] too much information really. But they focus it on where the abnormalities are being picked up so if they're persistently in the high blood pressure readings or high blood sugar readings, then I'd be notified by fax. So that might happen once or twice a week for example. But we have quite a few patients on the telehealth programme. (GP, Newham)

It was apparent that the GPs interviewed for this study were unfamiliar with the routine monitoring process. Instead they spoke about its introduction within the context of wider economic and health policy reforms, with some cautiously questioning the motives behind its introduction, which they speculated were driven principally by economics and the vested interests of the technology industry:

I think it's got to be explored in these strange times. I think you have to look at cheaper ways of doing it. And I think a lot of it is cost based. I think that's the motivation for a lot of, of the people doing it, I would imagine the Department of Health as well, but you have to be realistic in these times. (GP, Cornwall)

\section{DISCUSSION}

\section{Summary}

Most nursing staff held positive views on telehealth because they perceived it had an empowering impact on patients and on their own professional development. They accepted monitoring at a distance as a legitimate form of nursing practice and a potentially important means of facilitating patient self-management and education, provided it was consistent with and complementary to existing practice. The reporting of how the telehealth impacted on patients' capacity and capabilities to work with them resonates with work on established patients views of working with telecare ${ }^{19}$ and also with previous research showing that the views of technology were linked to views of professional selfimage and status and that professionals were concerned about the impact on the stability of existing patient professional relationships. ${ }^{14}$ Some potential patientfocused barriers to its implementation were also identified. 20,21

In contrast GPs held much more mixed views; some gave a cautious welcome but most saw telehealth as increasing their work burden and potentially undermining their professional autonomy and questioned the motives behind its introduction. Both GPs and nursing staff had reservations about the suitability of telehealth monitoring for the very severely ill and for patients with the lowest levels of illness.

Most GP participants had largely devolved long-term condition management to nurses and had not particularly engaged with telehealth. It was very clear from the interviews that many GPs felt overburdened and undermined and viewed telehealth as just one more imposition on their time. This is not surprising given the many recent changes imposed upon their practice. This was in stark contrast to the nurses who were generally enthusiastic and welcomed telehealth as providing opportunities to develop new skills and ways of working that would increase their confidence to work autonomously in the care of patients and to be able to communicate effectively with clinicians. Findings from this study also suggest that nurses are receptive to the idea of improving their skills and taking on more responsibility for patient care; they made numerous comments about taking on further professional education that would support the development of further telehealth training opportunities. However the different viewpoints may well relate to levels of experience and education about telehealth. When professionals actually engage with it they seem to like it.

\section{Strengths and limitations}

This article adds to the growing set of publications ${ }^{12,20-24}$ by the Whole System Demonstrator evaluation team and provides a unique insight into some of the 


\section{Funding}

This is an independent report commissioned and funded by the Policy Research Programme in the Department of Health. The views expressed are those of the authors and are not necessarily those of the Department of Health.

\section{Ethical approval}

The study was approved by Liverpool Research Ethics Committee (ref: 08/ H1005/4).

\section{Provenance}

Freely submitted; externally peer reviewed.

\section{Competing interests}

The authors have declared no competing interests.

\section{Acknowledgements}

Members of The Whole System Demonstrator Evaluation Team additional to specified authors include: Lorna Rixon, Catherine Henderson, Adam Steventon, Helen Doll, Martin Cartwright, Pete Bower, Shashivadan P Hirani, Theopisti Chrysanthaki, Michelle Beynon, John Billings, Andy Bowen, Jennifer Dixon, JoseLuis Fernandez, Luis A Silva and Jennifer Beecham.

\section{Discuss this article}

Contribute and read comments about this article: www.bjgp.org/letters challenges facing front-line professionals within the larger study. While the study was completed some time ago, it is unlikely that views will have fundamentally altered as little progress (in terms of large scale implementation) has been made and most healthcare staff will not have come across this technology.

The study has some methodological limitations. First, participant recruitment was reliant to a large extent on the cooperation of project managers and the gatekeeping role of some of the practice managers. This may have resulted in some bias in the sample selection process. Furthermore, the study was situated within a specific context and views of telehealth were not obtained from front-line nurses and GPs who did not take part in the study, so this small sample would not necessarily represent the full range of views and experiences on a subject. Nevertheless the strengths of the study lie in the rigorous qualitative methods used to focus on a group of people representing important viewpoints. This is an under-researched area and so is an important addition to the literature.

\section{Comparison with existing literature}

Previous qualitative research on telehealth largely focuses on organisational factors or patients experiences of telehealth ${ }^{20,21}$ and as in other studies there are similarities and differences between nurses and GPs in the way they perceive and understand the value of telehealth. The current study found a general acceptance of telehealth by the nurses. While nurses perceived telehealth as an empowering and educational selfcare tool for patients, there was some concern that patients were being drawn into medical work. ${ }^{3}$ The notion of clinical surveillance was also a theme identified elsewhere, ${ }^{20,25}$ where it was cited by patients as either a reason for declining telehealth or as reassurance arising from perceived clinical monitoring. Views on assessment are in accordance with a recent study which recommended a targeted approach. ${ }^{25,26}$ However the views of GPs were mixed and many took a broader but somewhat negative view, echoing other studies that have drawn such themes as reduced clinical autonomy and external control. 9.27,28 This is in contrast to another study which found that GPs were enthusiastic about teleheath, although this may be because they were fully involved in monitoring their patients. ${ }^{28}$

\section{Implications for practice}

GPs have delegated much of the care of patients with long-terms conditions to nurses but maintain their traditional positions of authority because of their professional status and their control over resource allocation at local level. However innovative technological advances in health care are inevitable and the results of this study and subsequent research by Segar et al ${ }^{9}$ have drawn attention to the contribution of telehealth to the increasingly complex primary healthcare roles and working practices. The results of this study indicate that primary healthcare professionals have been grappling with how to manage boundaries and identities that the introduction of telehealth has brought about, and so work is required for them to develop a shared understanding and to re-negotiate and delineate their own roles and responsibilities in relation to telehealth and patients as an enabling healthcare practice.

Further testing and development of telehealth is likely to be most promising if it is focused on the working environment and training needs of nurses. 


\section{REFERENCES}

1. Nicolini D. The work to make telemedicine work: a social and articulative view. Soc Sci Med 2006; 62(11): 2754-2767

2. Oudshoorn N. Physical and digital proximity: emerging ways of health care in face-to-face and telemonitoring of heart-failure patients. Social Health Illn 2009; 31(3): 390-405.

3. Harrison R, MacFarlane A, Murray E, et al. Patients' perceptions of joint teleconsultations: a qualitative evaluation. Health Expect 2006; 9(1): 81-90.

4. Lamothe L, Fortin J-P. Labbe F, et al. Impacts of telehomecare on patients, providers, and organizations. Telemed J E Health 2006; 12(3): 363-369.

5. Newman S, Steed E, Mulligan K. Chronic physical illness: self management and behavioural interventions. Columbus, OH: McGraw-Hill International, 2008.

6. Gagnon M-P, Duplantie J, Fortin J-P, et al. Implementing telehealth to support medical practice in rural/remote regions: what are the conditions for success. Implement Sci 2006; 1(18): 1-8.

7. Whitten P, Sypher BD. Evolution of telemedicine from an applied communication perspective in the United States. Telemed J E Health 2006; 12(5): 590-600.

8. Al-Qirim NA. Critical success factors for strategic telemedicine planning in New Zealand. Telemed J E Health 2005; 11(5): 600-607.

9. Segar J, Rogers A, Salisbury C, et al. Roles and identities in transition: boundaries of work and inter-professional relationships at the interface between telehealth and primary care. Health Soc Care Community 2013; 21(6): 606-613.

10. Pinnock $H$, Hanley J, McCloughan L, et al. Effectiveness of telemonitoring integrated into existing clinical services on hospital admission for exacerbation of chronic obstructive pulmonary disease: researcher blind, multicentre, randomised controlled trial. BMJ 2013; 347: $\mathbf{6 0 0 7 0 .}$

11. Bardsley M, Steventon A, Doll H. Impact of telehealth on general practice contacts: findings from the whole systems demonstrator cluster randomised trial. BMC Health Serv Res 2013; 13(1): 395.

12. Bower $\mathrm{P}$, Cartwright $\mathrm{M}$, Hirani SP, et al. A comprehensive evaluation of the impact of telemonitoring in patients with long-term conditions and social care needs: protocol for the whole systems demonstrator cluster randomised trial. BMC Health Serv Res 2011; 11(1): 184

13. Ferlie E, Fitzgerald L, Wood M, et al. The nonspread of innovations: the mediating role of professionals. Acad Manage J 2005; 48(1): 117-134.

14. Hibbert D, Mair FS, May CR, et al. Health professionals' responses to the introduction of a home telehealth service. Journal Telemed Telecare 2004: 10(4): 226-230.

15. Hopp FP, Hogan MM, Woodbridge PA, et al. The use of telehealth for diabetes management: a qualitative study of telehealth provider perceptions. Implement Sci2007: 2(1): 14 .

6. Nicolini D. Stretching out and expanding work practices in time and space: The case of telemedicine. Human Relations 2007; 60(6): 889-920.

17. Oudshoorn N. Diagnosis at a distance: the invisible work of patients and healthcare professionals in cardiac telemonitoring technology. Sociol Health IIl 2008; 30(2): 272-288.

18. Pope C, Ziebland S, Mays, N. Analysing qualitative data. BMJ 2000; 320(7227): $114-116$.

19. Rogers A, Kirk S, Gately C, et al. Established users and the making of telecare work in long term condition management: implications for health policy. Soc Sci Med 2011; 72(7): 1077-1084

20. Sanders C, Rogers A, Bowen R, et al. Exploring barriers to participation and adoption of telehealth and telecare within the Whole System Demonstrator trial: a qualitative study. BMC Health Serv Res 2012; 12(1): 220

21. Hendy J, Chrysanthaki T, Barlow J, et al. An organisational analysis of the implementation of telecare and telehealth: the whole systems demonstrator. BMC Health Serv Res 2012; 12(1): 403

22. Steventon A, Bardsley M, Billings J, et al. Effect of telehealth on use of secondary care and mortality: findings from the Whole System Demonstrator cluster randomised trial. BMJ 2012; 344: e3874.

23. Steventon A, Bardsley M, Billings J, et al. Effect of telecare on use of health and social care services: findings from the Whole Systems Demonstrator cluster randomised trial. Age Ageing 2013; 42(4): 501-508

24. Henderson C, Knapp M, Fernández J-L, et al. Cost effectiveness of telehealth for patients with long term conditions (Whole Systems Demonstrator telehealth questionnaire study): nested economic evaluation in a pragmatic, cluster randomised controlled trial. BMJ 2013: 346: £2065.

25. Fairbrother P, Ure J, Hanley J, et al. Telemonitoring for chronic heart failure: the views of patients and healthcare professionals - a qualitative study. J Clin Nurs 2014; 23(1-2): 132-144.

26. Middeke M. Telemedicine in chronic heart failure: patient selection is a prerequisite for success. Herz 2012; 37(1): 81-84.

27. Blickem C, Bower P, Protheroe J, et al. The role of information in supporting self-care in vascular conditions: a conceptual and empirical review. Health Soc Care Community 2011; 19(5): 449-459.

28. Jones MI, Greenfield SM, Bray EP, et al. Patients' experiences of self-monitoring blood pressure and self-titration of medication: the TASMINH2 trial qualitative study. Br J Gen Pract 2012; DOI: 10.3399/bjgp12X625201. 